\title{
Construction Professionals Understanding of Benefit of Stabilised Earth Construction in Urban Low-Cost Housing Crisis in Zimbabwe
}

\author{
Mohammad Sharif Zami* \\ Department of Architecture, King Fahd University of Petroleum \& Minerals, Saudi Arabia
}

Submission: August 20, 2018; Published: September 06, 2018

*Corresponding author: Mohammad Sharif Zami, Department of Architecture, King Fahd University of Petroleum \& Minerals, Saudi Arabia; Tel: 9.66567E+11; Email: mdszami@kfupm.edu.sa

\begin{abstract}
Stabilised earth is an alternative construction material which is economically and environmentally beneficial compared to the conventional material such as baked brick and concrete. Earth is used as a construction material in every continent since the earliest civilisation. Existing literature shows that the use of earth as a building material saves cost, time, energy, and reduces environmental pollution. This paper critically reviews the literatures and come up with a generic list of benefits of earth construction. A series of in-depth interviews then investigate and ascertain from the Zimbabwean construction professionals whether stabilised earth construction is beneficial in in urban low-cost housing in Zimbabwe
\end{abstract}

Keywords: Construction; Stabilised earth; Benefit; Urban; Low cost housing

\section{Introduction}

A number of Delphi and In-depth interviews with earth construction experts carried out by the author in 2008 reveals that some experts do not at all support the promotion of stabilised earth construction as they generally perceive, stabilised earth construction means cement stabilised earth construction. In spite of the fact that stabilised earth is a low energy alternative and could be cost effective in many situations, its accessibility to the rural/ urban poor is far from satisfactory; and while stabilised earth construction is less costly than brick masonry, it is still often more expensive than what the majority of the poor can afford [1]. Besides, it is unfortunate that many practitioners of systematic stabilisation do not know, or do not appreciate the original characteristics of a soil and start about stabilising soil with undue haste when it is not particularly useful [2]. In addition, the majority of disadvantages (i.e. problems of earth wall erosion by rain and flood water, rodents making holes in wall and floor, and poor performance during earthquakes) associated with mud houses (un-stabilised earth) can be overcome by

Table 1: Benefits of earth construction.

\begin{tabular}{|c|c|c|}
\hline S No & Benefits & Author \\
\hline & (Summarised from the literature review) & {$[1,3,4,6,8,12,16-19,22,24]$} \\
\hline 1 & Earth construction is economically beneficial. & {$[1,6,8,12,16,17,19]$,} \\
\hline 2 & It requires simple tools and less skilled labour. & \\
\hline
\end{tabular}

suitable improvements in design and technology, such as soil stabilisation, appropriate architecture, and improvement in structural techniques [3]. It is also noted that, the definition and meaning of stabilised earth construction is understood wrongly amongst the earth construction professionals and experts [45]. This paper aims to explore the benefit of stabilised earth construction in Zimbabwean urban low-cost housing context. Furthermore, to achieve the aim, the author critically reviews relevant literature and adopts the in-depth interview method to analyse and validate the benefits of stabilised earth construction in Zimbabwe urban low-cost housing. The following section reviews the current state of art review of benefits of stabilised earth construction to establish a base for the in-depth interviews as to compare and contrast the literature against Zimbabwean construction professional perspectives.

\section{State of art review on benefits of earth construction}

Table 1 lists the benefits of earth construction from the intensive literature review: - 


\section{Civil Engineering Research Journal}

\begin{tabular}{|c|c|c|}
\hline 3 & It encourages self-help construction. & {$[12,17]$} \\
\hline 4 & Suitable for very strong and secured structure. & {$[1,3,2,8,16,18,17]$,} \\
\hline 5 & It saves energy (low embodied energy). & {$[1,2,3,4,10,17,12,22,8,1]$} \\
\hline 6 & It balances and improves indoor air humidity and temperature. & {$[1,2,8,22]$} \\
\hline 7 & Earth is very good in fire resistance. & {$[1]$} \\
\hline 8 & Earth construction is regarded as a job creation opportunity. & {$[17]$} \\
\hline 9 & Earth construction is environmentally sustainable. & {$[4,17]$} \\
\hline 10 & Loam preserves timber and other organic materials. & {$[8,9,22,18,22]$} \\
\hline 11 & Earth walls (loam) absorb pollutants. & {$[2,8,12]$,} \\
\hline 12 & Easy to design with and high aesthetical value. & {$[7]$} \\
\hline 13 & Earth buildings provide better noise control. & {$[1,36,8,19]$} \\
\hline 14 & Earth construction promotes local culture, heritage, and material. & \\
\hline 15 & Earth is available in large quantities in most regions. & \\
\hline
\end{tabular}

Source: [27].

\section{Research Methodology}

After a critical review of the literatures, it appears that there is a lack of structured research to date carried out to identify the benefits of stabilised earth construction in Zimbabwe. In addition, the benefits identified by different practitioners and researchers mentioned in the literature lack empirical data and validation through a research methodological process. The benefits found in the literature are written in the light of the researchers experience and perception working with this building material. Therefore, the research technique adopted in this paper is in-depth interviews which effectively collects data from Zimbabwean construction professionals and compare the list of benefits found in the existing literature.

In order to understand the benefits, the in-depth interview method unlocked the vital experiences of the experts represented by the practitioners, academics and researchers. The aim of a researcher should be to ensure that the method used enable maximum convergence (transfer of meaning) between themselves and the respondent [6]. In Loosemore's [6] opinion, interviews are able to facilitate feedback through two-way communication. Interviews represent a powerful tool in the building of a theory, not only by eliciting perceptions of the concept from the experts, that is the industrial practitioners, but also, the theory-building process is supplemented by the contextualised data gathered from the stories of the practitioners' experiences [7]. The study of this paper executed in-depth interviews with experts who are experienced in the Zimbabwean construction industry.

Analysing in-depth interviews involves reviewing the records of the interviews and taking notes to keep track of the findings that are emerging and the two most common strategies for organising notes are: - Organising by question and theme. Both strategies may be used concurrently; for example, content analysis can be begun by organising by question, but switch to a thematic strategy as themes emerge over the course of the interviews [8]. The researcher of this study used both strategies concurrently to analyse the data. In-depth interviews are flexible in that they can be presented in many ways; there is no specific format to follow [9].

Boyce \& Neale [9] stated that providing quotes from respondents throughout the report adds credibility to the information. The researcher should be careful that the respondent is not identified or provide quotes that are easily traced back to an individual, especially if confidentiality is promised. In-depth interview data can be displayed in tables, boxes, and figures to make it easier to read. The aim of the in-depth interview is to refine and validate the generic list of benefits derived from the literature review considering Zimbabwean context. The benefits refined by the in-depth interviews are based on the opinions of the Zimbabwean construction professionals and lead to an understanding of the benefits of stabilised earth construction in Zimbabwe. It is worth mentioning here that there are very few Zimbabwean earth construction experts whom have worked or are at present working in Zimbabwe. Therefore, in essence, data was collected through face to face interviews with four experts and telephone conversations with four more experts. The political and economic problems of Zimbabwe drove away most of the experienced and qualified Zimbabwean construction professionals to the neighbouring countries and other developed countries. Therefore, conducting the interviews in Zimbabwe was not possible as the majority of experienced construction professionals had migrated.

A total of fourteen (14) experts were contacted through email. Telephone calls were made to follow up the invitation of the experts to take part in the interview. Eight (08) experts agreed to take part in the interview pertaining to this study. Three (03) of the experts were academician researchers with an average of over thirty years work experience. The remaining five (05) experts were practitioners with an average of eight years practical experience. In choosing experts for this in-depth interview, a set of criteria were considered and accordingly a list of eight (08) experts were identified from the private and public 


\section{Civil Engineering Research Journal}

sector that would have the required knowledge and experience of the subject.

\section{Finding the benefits of stabilised earth construction in Zimbabwe from the in-depth interviews}

At first, all experts were asked independently without informing them of the generic list of benefits identified from the literature review whether or not stabilised earth construction is beneficial in Zimbabwe. Interviewees were given this opportunity to express their own opinions and list the benefits other than the ones to be validated. Two experts thought that stabilised earth construction is beneficial upon certain conditions (see Table 2). Therefore, the broad answer is 'yes' but it is project specific. One must ask what the potential benefits are, and these have to be weighed against what the alternatives are and what the particular economic problems the country is experiencing at the moment are. According to one of the experts primarily the biggest driver in terms of the benefit of earth building in Zimbabwe would have to be the cost as he stated that, "If one can't afford it in Zimbabwe nobody is going to use it. Therefore, the economic benefit of earth construction has to be the major benefit of this technology in Zimbabwe, and as well as a major part of the developing countries, where labour is relatively affordable and cheap." Summary, of the conditions upon which the stabilised earth construction in Zimbabwe is beneficial are summarised and displayed in Table 2.

Table 2: Benefits of stabilised earth construction in Zimbabwe validated by the experts.

\begin{tabular}{|c|c|}
\hline S No & Benefits (Validated and Summarised from the In-Depth Interviews) \\
\hline 1 & Earth construction is economically beneficial in Zimbabwe. \\
\hline 2 & It requires simple tools and less skilled labour in Zimbabwe. \\
\hline 3 & Suitable for very strong and secure structures. \\
\hline 4 & It saves energy (low embodied energy). \\
\hline 5 & It balances and improves indoor air humidity and temperature. \\
\hline 6 & Earth construction is regarded as a job creation opportunity in Zimbabwe. \\
\hline 7 & Earth construction is environmentally sustainable. \\
\hline 8 & Easy to design with high aesthetical value. \\
\hline 9 & Earth buildings provide better noise control. \\
\hline 10 & Earth construction promotes Zimbabwean local culture, heritage, and material. \\
\hline 11 & It encourages self-help construction. \\
\hline 12 & Earth is available in large quantities in most regions in Zimbabwe. \\
\hline 13 &
\end{tabular}

According to experts un-stabilised earth construction gives rise to a lot of benefits whereas stabilised earth construction brings very few, if any, as expert states, "the major issue with urban housing procurement and construction is funding, as it all comes down to the cost of industrial inputs. People simply cannot afford cement; therefore, if cement is added into a product then immediately it runs into all the same problems that urban housing in Zimbabwe has." According to expert, most places in Zimbabwe have sui Table 3 soil for stabilised earth construction. Moreover, expert stated that, "the rural population always wish to build with brick, concrete and upgrade their way of living. Nevertheless, if one can persuade them that earth is an acceptable building material from the social point of view then they are already familiar with it. If their understandable reservations can be overcome, their traditional familiarity with this material will enable them to use it with skill". The statements supported that the suitable soil and local skill set of earth construction are available in Zimbabwe. Five experts unanimously agreed that stabilised earth construction is beneficial in Zimbabwean urban low-cost housing.

Table 3: Conditions and circumstances upon which stabilised earth construction is beneficial in urban low-cost housing.

\begin{tabular}{|c|c|c|}
\hline Conditions and Circumstances & $\begin{array}{l}\text { Literature } \\
\text { Review }\end{array}$ & $\begin{array}{l}\text { In-depth } \\
\text { Interview }\end{array}$ \\
\hline $\begin{array}{l}\text { Availability of local soil, as opposed to the need to be sourced from a great distance resulting in increased costs } \\
\text { because of transportation. Therefore, Soil should be dug locally. }\end{array}$ & $\checkmark$ & $\checkmark$ \\
\hline $\begin{array}{l}\text { Type of stabiliser. Un-stabilised could be more appropriate. As a rule, it is only necessary to modify the } \\
\text { characteristics of loam (earth) for special application. In addition, suitability of the soil for stabilisation, and thus the } \\
\text { type, quality and quantity of stabiliser needed. It may also be necessary to buy sand if the soil has an excessively high } \\
\text { linear shrinkage. }\end{array}$ & $\checkmark$ & $x$ \\
\hline $\begin{array}{l}\text { The earth construction project needs to compare with the other locally available alternative construction techniques } \\
\text { in terms of cost (especially stabiliser). Therefore, the benefit of earth construction is project specific. }\end{array}$ & $\checkmark$ & $\checkmark$ \\
\hline Skilled labour should be available in the locally. & $x$ & $\checkmark$ \\
\hline
\end{tabular}




\section{Civil Engineering Research Journal}

\begin{tabular}{|c|c|c|}
\hline The design team should be skilled in earth construction, in order to do it correctly. & $\mathbf{x}$ \\
\hline Whether the blocks are to be made in rural or urban areas, the size and type of equipment used and quality required. & $\checkmark$ & $\mathbf{x}$ \\
\hline Current wage rates and productivity of the labour force. & $\checkmark$ & $\mathbf{x}$ \\
\hline
\end{tabular}

Experts were then shown the generic list of benefits identified from the literature review and were asked to validate whether those benefits of stabilised earth construction were applicable in Zimbabwean urban low-cost housing. All experts agreed and validated that the list of benefits shown to them as benefits of stabilised earth construction except benefits 10 and 11 (Table 1) because these need to be backed by more empirical evidence. According to expert's air pollution is not a big threat in Zimbabwe and the production of earth building material consumes less energy and has minimal environmental effects, therefore, the benefits ' 10 ' and ' 11 ' are not necessary in a Zimbabwean context. The summary of the benefits validated by the in-depth experts is listed in Table 2.

1. Zimbabwean local culture, heritage, and material.

2. It encourages self-help construction.

3. Earth is available in large quantities in most regions in Zimbabwe.

In the in-depth interviews it was found that stabilised earth construction is beneficial in urban low-cost housing but dependent upon certain conditions and circumstances. It is notable that the conditions identified in the literature review are causes only for cost variations of stabilised earth construction. The conditions and circumstances upon which the benefits are dependent identified in literature review and in-depth interview are summarised and shown in Table 3.

Therefore, the above conditions and circumstances in Table 3 need to be considered to assess the benefits of any stabilised earth construction project in Zimbabwean urban lowcost housing. It is important to note that the literature review identified fifteen (15) benefits and in-depth interview identified thirteen (13) benefits of stabilised earth construction in housing. According to the majority of experts, the economic benefit has become the major benefit of this technology in Zimbabwe as well as a major part of the developing countries where labour is relatively affordable and cheap [10-27].

\section{Conclusion}

The construction professionals participated in the indepth interview agreed that stabilised earth construction in Zimbabwe urban low-cost housing is beneficial dependent on some conditions and circumstances. Therefore, if the typologies of urban housing, availability of the suitable soil locally sourced, appropriate climatic conditions, the typologies of stabilizer are appropriate for this kind of construction, then stabilised earth construction is beneficial building urban low-cost housing in Zimbabwe. The use of earth as a construction material with an innovative approach would apply well and can be considered as a sustainable solution to the urban low-cost housing crisis. Promotion and adoption of earth as an alternative lowcost urban house construction material is worthwhile and significantly helpful in achieving environmental sustainability (less carbon dioxide emission and less energy used) and reducing construction cost. Besides, in earth construction individuals and community as a whole can easily participate in building their own homes in an affordable way.

\section{References}

1. Jagadish KS (2007) Earth construction today: prospects and tasks International Symposium on Earthen Structures, Indian Institute of Science, Interline Publishing, Bangalore, India.

2. Houben H, Guillaud H (1994) Earth construction-A comprehensive guide. Intermediate Technology publications, London.

3. Lal AK (1995) Handbook of low cost housing. New Age International Publishers, New Delhi, India.

4. Zami MS, Lee A (2009) Contemporary earthen architecture in urban Bangladesh-a solution to carbon dioxide emissions in the era of climate change. Bangladesh University of Engineering \& Technology (BUET), Dhaka, Bangladesh.

5. Zami MS, Lee A (2009) Archnet-IJAR. International Journal of Architectural Research 3(2): 51-65.

6. Loosemore M (1999) International construction management research: cultural sensitivity in methodological design. Construction management and economics 17: 553-561.

7. Chan PW (2004) An Interpretivistic approach to understand the factors that affect construction labour productivity. PhD Thesis submitted to Heriot-Watt University, Edinburgh, United Kingdom.

8. Wallace Foundation Website (2009) Workbook E: Conducting InDepth Interviews.

9. Boyce C, Neale P (2016)

10. Adam EA, Agib ARA (2016)

11. Alphonse SS (1985) General report, Appropriate Building Materials for Low cost Housing, African region. Proceedings of a symposium held in Nairobi, Kenya, London, New York, USA

12. Cassell RO (1993) A traditional research paper: Rammed Earth Construction. The compaction of successive layers of earth between forms to build a wall.

13.Easton D (1996) The Rammed Earth House. Chelsea Publishing Company, White River Junction, Vermont, USA.

14. Frescura F (1981) Rural Shelter in Southern Africa. Ravon Press, Johannesburg, RSA.

15. Hadjri K, Osmani M, Baiche B, Chifunda C (2007) Attitude towards earth building for Zambian housing provision. Proceedings of the ICE institution of civil engineers, engineering sustainability 160, issue ES3. ICE Publisher, UK.

16. Howieson S (2005) Housing \& Asthma.

17. Kateregga JK (1983) Improvement and use of earth construction products for low cost housing. Appropriate Building Materials for Low cost Housing, African region. Proceedings of a symposium held in Nairobi, Kenya, London, New York, USA. 


\section{Civil Engineering Research Journal}

18. Kelly G (1970) A brief introduction to personal construct theory. In: Bannister, D (Ed.) Perspectives in personal construct theory. Academic press, London, p. 1-29.

19. Maini S (2005) Earthen architecture for sustainable habitat and compressed stabilised earth block technology. The Auroville Earth Institute, Auroville Building Centre, India.

20. Minke G (2006) Building with earth, design and technology of a sustainable architecture. Birkhauser publishers for architecture, SSBasel, Berlin, Boston, USA.

21. Morton T (2007) Towards the development of contemporary Earth Construction in the UK: drivers and benefits of Earth Masonry as a Sustainable Mainstream Construction Technique. International Symposium on Earthen Structures, Indian Institute of Science, Interline Publishing, Bangalore, India, p. 22-24.

22. Morris J, Booysen Q (2000) Earth construction in Africa. Proceedings: strategies for a sustainable Built Environment, Pretoria, South Africa.
23. Ngowai AB (2000) The conflict between survival and sustainability. Proceedings: international conference sustainable building, Netherlands.

24. Pidd M (1996) Tools for thinking: modelling in management science. John Wiley, Chichester, England.

25. Walker P, Keable R, Martin J, Maniatidis V (2005) Rammed earth: Design and Construction Guidelines. BRE Bookshop, Zimbabwe.

26.Zami MS, Lee A (2007) The influence of housing standards in the development of low cost sustainable housing in Zimbabwe. The $7^{\text {th }}$ International Postgraduate Research Conference. The Lowry, Salford Quays, Salford, Greater Manchester, UK.

27. Zami MS (2010) Understanding the factors that influence the adoption of stabilised earth by construction professionals to address the Zimbabwe urban low-cost housing crisis. PhD thesis submitted to University of Salford, UK.

\section{Your next submission with Juniper Publishers will reach you the below assets}

- Quality Editorial service

- Swift Peer Review

- Reprints availability

- E-prints Service

- Manuscript Podcast for convenient understanding

- Global attainment for your research

- Manuscript accessibility in different formats

( Pdf, E-pub, Full Text, Audio)

- Unceasing customer service

Track the below URL for one-step submission

https://juniperpublishers.com/online-submission.php 